OPEN ACCESS

Edited by: Samuel Abiven,

University of Zurich, Switzerland

Reviewed by: Frederic Jacques,

TFS, France

Sanping Xie,

Lanzhou University, China

${ }^{*}$ Correspondence:

Hua Zhu,

Xishuangbanna Tropical Botanical

Garden, Chinese Academy of

Sciences, Xue-Fu Road 88, Kunming,

Yunnan 650223, China zhuh@xtbg.ac.cn

Specialty section: This article was submitted to Biogeoscience,

a section of the journal

Frontiers in Earth Science

Received: 03 July 2015 Accepted: 02 September 2015 Published: 15 September 2015

Citation:

Zhu H (2015) Geographical patterns of Yunnan seed plants may be influenced by the clockwise rotation of the

Simao-Indochina geoblock.

Front. Earth Sci. 3:53. doi: $10.3389 /$ feart.2015.00053

\section{Geographical patterns of Yunnan seed plants may be influenced by the clockwise rotation of the Simao-Indochina geoblock}

\author{
Hua Zhu * \\ Xishuangbanna Tropical Botanical Garden, Chinese Academy of Sciences, Kunming, China
}

Floristic patterns of seed plants in Yunnan, southwestern China, were studied to assess the relationship between the floristic geography and geological history. A database of 38 regional floristic studies covering Yunnan was used and the patterns of seed plant distributions across these regional floras were quantified at the generic level. Genera with tropical Asian distributions are the most dominant geographical elements in the Yunnan flora. They show oblique patterns of abundance across Yunnan. They are most abundant in southern and western Yunnan, and their proportion in regional floras declines abruptly in eastern, central and northern Yunnan. The oblique abundance patterns of geographical elements in Yunnan differ from those of genera in southern and eastern China, which had a high correlation with latitudinal gradients controlled by climate. They cannot be explained by climate alone, but can be explained at least partly by the geological history. The oblique abundance patterns of Yunnan seed plants correspond well to the clockwise rotation and southeastward extrusion of the Simao-Indochina geoblock caused by the collision of India with Asia.

Keywords: distribution patterns, geographical elements, Simao-Indochina geoblock, Yunnan, southwestern China

\section{Introduction}

Yunnan province in southwest China $\left(21^{\circ} 09^{\prime}\right.$ and $29^{\circ} 15^{\prime} \mathrm{N}, 97^{\circ} 32^{\prime}$ and $106^{\circ} 12^{\prime}$ E; Figure 1) is situated in a transitional zone between tropical south-east Asia and temperate Himalayas, and it has a mountainous topography with elevation ranges from $76.4 \mathrm{~m}$ at the lowest valley bottom in the southeast (Red River) to $6740 \mathrm{~m}$ at the highest mountain summit in the northwest (Figure 2). Yunnan is extremely diverse in habitats and biodiversity. Southern Yunnan with a tropical monsoon climate has a tropical flora of Malaysian affinity (Zhu, 1997, 2008a; Zhu and Yan, 2009a). Central Yunnan with a subtropical climate is largely characterized by a subtropical flora of East Asian affinity (Yan et al., 2009). Northwestern Yunnan, with a temperate climate and alpine-deep valley topography, has a temperate Himalayan flora (Zhu, 2009, 2015).

Studies of the floristic patterns of Yunnan seed plants reveal that the majority of genera found in southern, southwestern and southeastern Yunnan are tropical, while the majority of genera found in northern Yunnan are temperate (Zhu, 2008b, 2012). Among the tropical genera, tropical Asian genera are most common. The abundances of these tropical Asian genera show oblique patterns across Yunnan, not latitudinal gradients as they are in southern and eastern China (Zhu et al., 2007). 


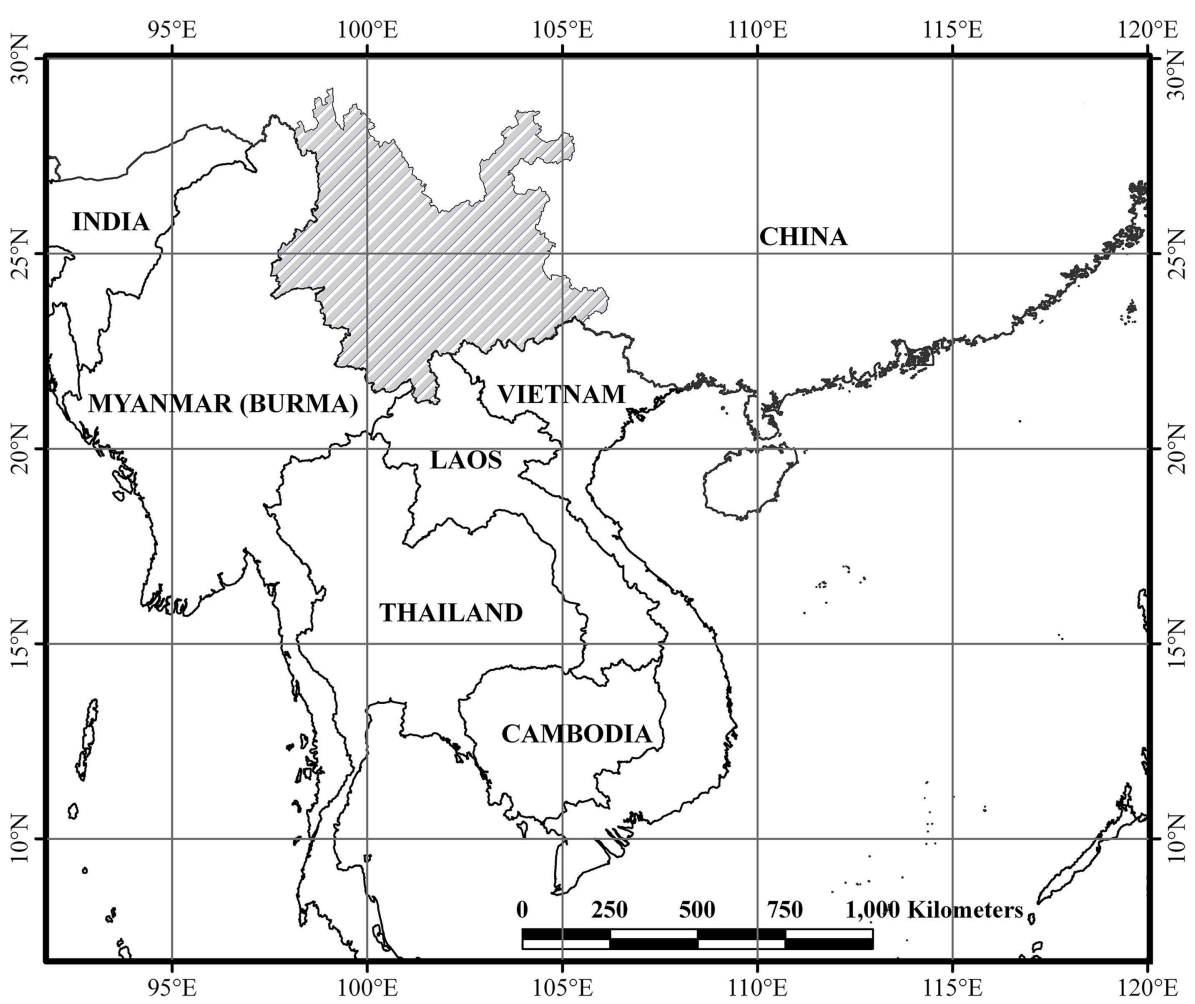

FIGURE 1 | Location of Yunnan (oblique dashed area), southwest China.

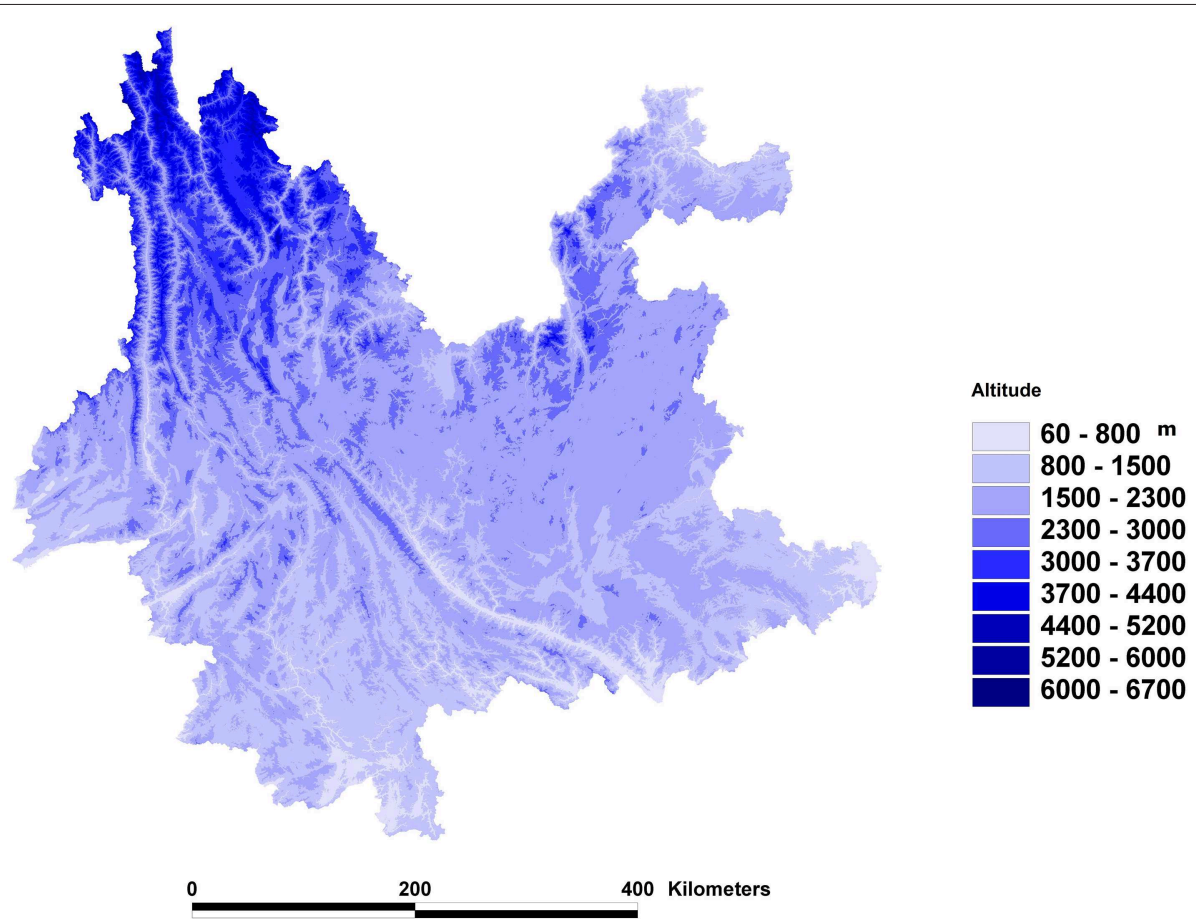

FIGURE 2 | Topography of Yunnan Province. 
TABLE 1 | The geographical elements at generic level among the sites (regional flora) from references data.

\begin{tabular}{|c|c|c|c|c|c|c|c|}
\hline Research sites & Longitude & Latitude & $\mathbf{P T} * \%$ & $\mathbf{T A}^{\star} \%$ & $\mathrm{TT} * \%$ & $\mathrm{EA}^{\star} \%$ & References \\
\hline Ailao Mts. NR & 101.20 & 24.20 & 20.36 & 25.91 & 21.47 & 11.23 & Zhu and Yan, 2009b \\
\hline Bulong NR & 101.00 & 22.00 & 22.33 & 37.52 & 9.91 & 3.69 & Zhu et al., 2015 \\
\hline Caiyanghe NR & 101.18 & 22.57 & 23.40 & 38.24 & 11.51 & 4.48 & Zhu et al., 2006a \\
\hline Cangshan NR & 100.00 & 25.45 & 18.75 & 9.45 & 37.07 & 13.81 & Duan, 1995 \\
\hline Dawei Mountain NR & 103.75 & 22.83 & 18.75 & 37.00 & 13.85 & 8.46 & Wang et al., 2006a \\
\hline Dazhong Mt. NR & 100.85 & 24.53 & 24.24 & 17.08 & 27.82 & 12.12 & Ding et al., 2006 \\
\hline Dulongjiang NR & 98.33 & 28.25 & 16.99 & 18.11 & 33.66 & 14.1 & Li, 1994 \\
\hline Gaoligong Mt. NR & 98.38 & 27.94 & 17.57 & 20.02 & 27.57 & 14.43 & Li et al., 2000 \\
\hline Gulinqing NR & 104.39 & 23.00 & 19.00 & 39.3 & 9.2 & 7.1 & Kong, 2008 \\
\hline Haba Snow Mt. NR & 100.15 & 27.25 & 13.98 & 4.1 & 43.9 & 14 & Yunnan Forestry Survey Institute, 2009 \\
\hline Huanglianshan NR & 102.15 & 22.95 & 21.66 & 37.28 & 12.31 & 7.57 & Xu, 2003 \\
\hline Jiaozixueshan NR & 102.80 & 26.20 & 13 & 6.9 & 43 & 12.1 & $\begin{array}{l}\text { Kunming Institute of Botany Chinese Academy } \\
\text { of Sciences and Kunming Forestry Bureau, } \\
2009\end{array}$ \\
\hline Jinguang Temple NR & 99.50 & 25.15 & 19.19 & 22.12 & 25.25 & 12.77 & Liu and Du, 1991 \\
\hline Langping Yunling NR & 99.35 & 26.5 & 19.45 & 10.85 & 42.04 & 13.2 & Yunnan Forestry Survey Institute, 2010 \\
\hline Lujiangba dry-hot valley & 98.90 & 25.00 & 41.3 & 13.9 & 8.8 & 2.7 & Cao, 1993 \\
\hline Nangunhe NR & 99.00 & 23.45 & 24.40 & 38.1 & 10.39 & 4.62 & Yang and Du, 2004 \\
\hline Nanpeng River NR & 99.00 & 23.90 & 20.45 & 30 & 15.22 & 7.58 & Zhang et al., 2010 \\
\hline Northern Gaoligong Mt. NR & 98.50 & 28.00 & 14.8 & 17 & 33.2 & 17.5 & Li et al., 2007 \\
\hline Nuozadu NR & 100.43 & 22.68 & 25.19 & 35.39 & 11.34 & 4.53 & Cao, 2004 \\
\hline Qiaojia dry-hot valley & 103.00 & 27.00 & 34.00 & 11.2 & 24.2 & 5.3 & Cao and Jing, 1989 \\
\hline Ruili Forest Park & 97.80 & 24.00 & 24.90 & 35 & 10.1 & 2.1 & Zhu et al., 2006b \\
\hline Shilin NR & 103.34 & 24.79 & 22.22 & 13.67 & 30.34 & 8.97 & Cui et al., 2005 \\
\hline Shishan NR & 102.86 & 25.46 & 21.58 & 9.34 & 37.76 & 12.24 & Guo, 1988 \\
\hline Southern Gaoligong Mt. NR & 98.76 & 24.83 & 25 & 31.26 & 18.8 & 7.8 & Meng et al., 2013 \\
\hline Tongbiguan NR & 97.65 & 24.65 & 20.42 & 33.8 & 14.97 & 9.24 & Yin et al., 2007 \\
\hline Wuding region & 102.00 & 25.83 & 20.38 & 11.43 & 32.35 & 10.27 & Li et al., 2009 \\
\hline Wuliangshan NR & 100.65 & 24.38 & 21.03 & 24.27 & 20.82 & 11.19 & Peng, 1997 \\
\hline Xianggelila county & 99.92 & 27.87 & 13.64 & 6.83 & 45.58 & 14.57 & Li and Zeng, 2006 \\
\hline Xiaobaicaoling NR & 101.07 & 26.12 & 19.62 & 10.58 & 39.04 & 12.5 & Wang et al., 2005 \\
\hline Xiaoheishan NR & 98.70 & 24.65 & 21.06 & 26.49 & 19.29 & 10.46 & Wang et al., 2006b \\
\hline Xishuangbanna NR & 101.50 & 21.50 & 19.6 & 51.5 & 3.9 & 1.5 & Zhu, 1993 \\
\hline Yongde Daxueshan NR & 99.80 & 24.10 & 18.08 & 22.15 & 22.93 & 11.41 & Liu and Peng, 2010 \\
\hline Yuanmou dry-hot valley NR & 101.89 & 25.78 & 41.88 & 8.97 & 19.22 & 5.13 & Li et al., 2008 \\
\hline Yulongxueshan NR & 100.32 & 27.18 & 17.06 & 5.29 & 47.25 & 12.16 & Ou, 1988 \\
\hline Yunajiang NR & 102.00 & 23.67 & 23.69 & 24.92 & 16.88 & 7.54 & Ma et al., 1995 \\
\hline Yunlong NR & 102.43 & 25.50 & 17.42 & 11.74 & 43.57 & 10.61 & Li et al., 2004 \\
\hline Zhaotong Region & 104.57 & 27.78 & 15.47 & 12.19 & 33.27 & 14.53 & Ding et al., 2008 \\
\hline Zixishan Natural Reserve & 101.40 & 24.50 & 19.74 & 10.26 & 40 & 10 & Li et al., 2010 \\
\hline
\end{tabular}

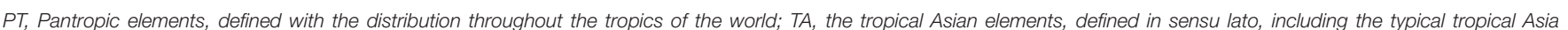

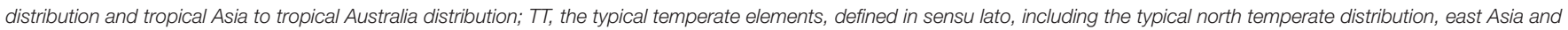
north America disjunct, and Old World temperate distributions; EA, East Asia elements, defined with the distribution from east Himalayas to Japan.

Biogeographical divergence of the flora of Yunnan was initiated by the uplift of the Himalayas and the extrusion of the Indochina block during the Tertiary (Zhu, 2012). The Indian continent collided with Asia at about $50 \mathrm{Ma}$ (Rowley, 1996) causing uplift of the Himalayas, continuous deformation of southwestern China and a large clockwise rotation and southeastward extrusion of Indochina (Harrison et al., 1992; Funahara et al., 1993; Chen et al., 1995; Leloup et al., 1995). The Simao Terrane, which forms the present west and south parts of
Yunnan, has been suggested as one of the prominent fragments of the extruded Indochina block (Sato et al., 1999, 2001, 2007). As a whole, the Simao Terrane was displaced southward by $800 \mathrm{~km}$, together with a clockwise rotation of $30^{\circ}$. The rotation processes were believed active until at least the Miocene (Schärer et al., 1990; Chen et al., 1995). These geological events may thus have affected the evolution of the Yunnan flora.

It is interesting to know whether the distribution patterns of seed plants in Yunnan have been affected by geological events. In 


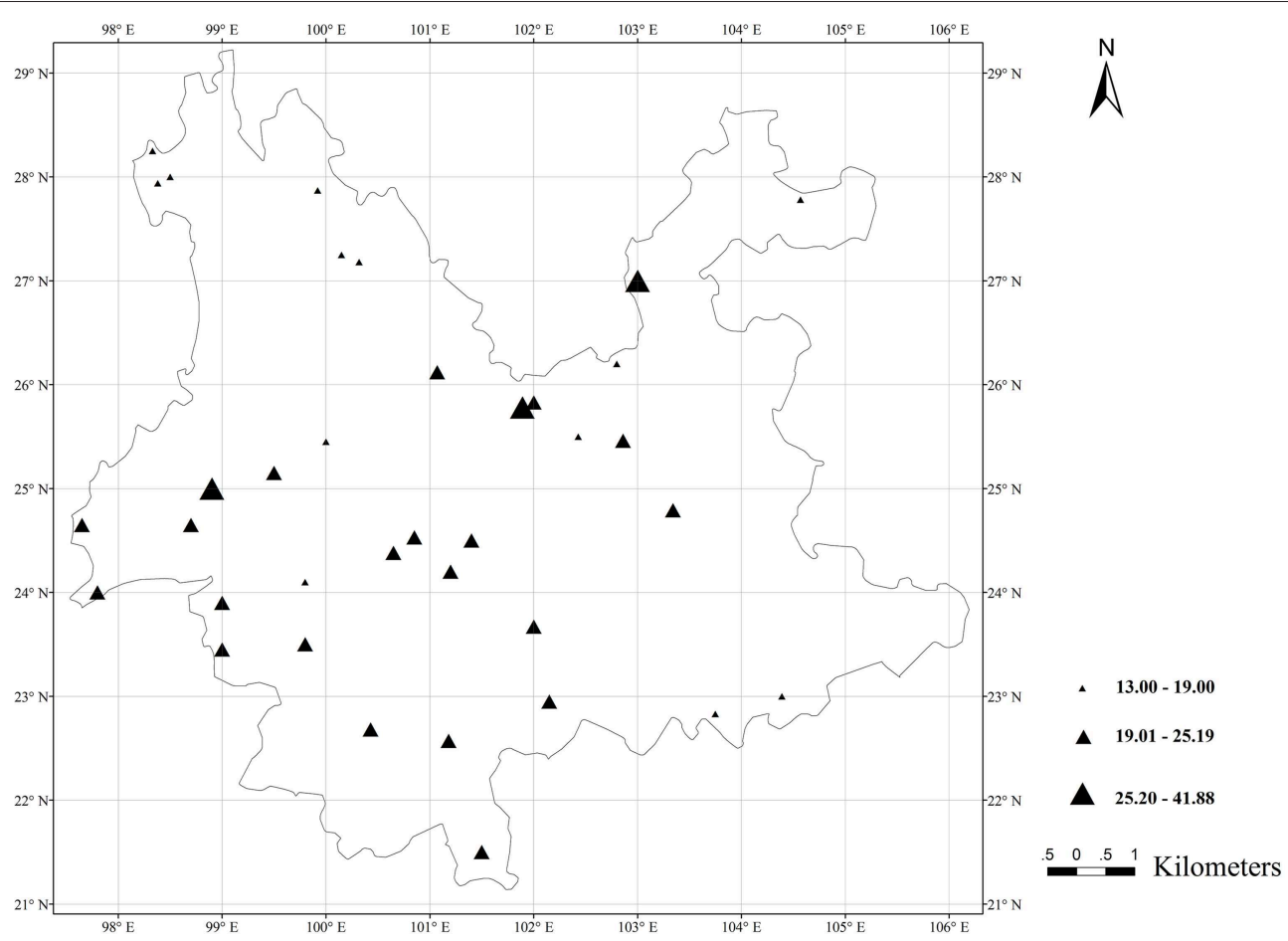

FIGURE 3 | The abundance pattern of the pantropic distributions of geographical elements across Yunnan.

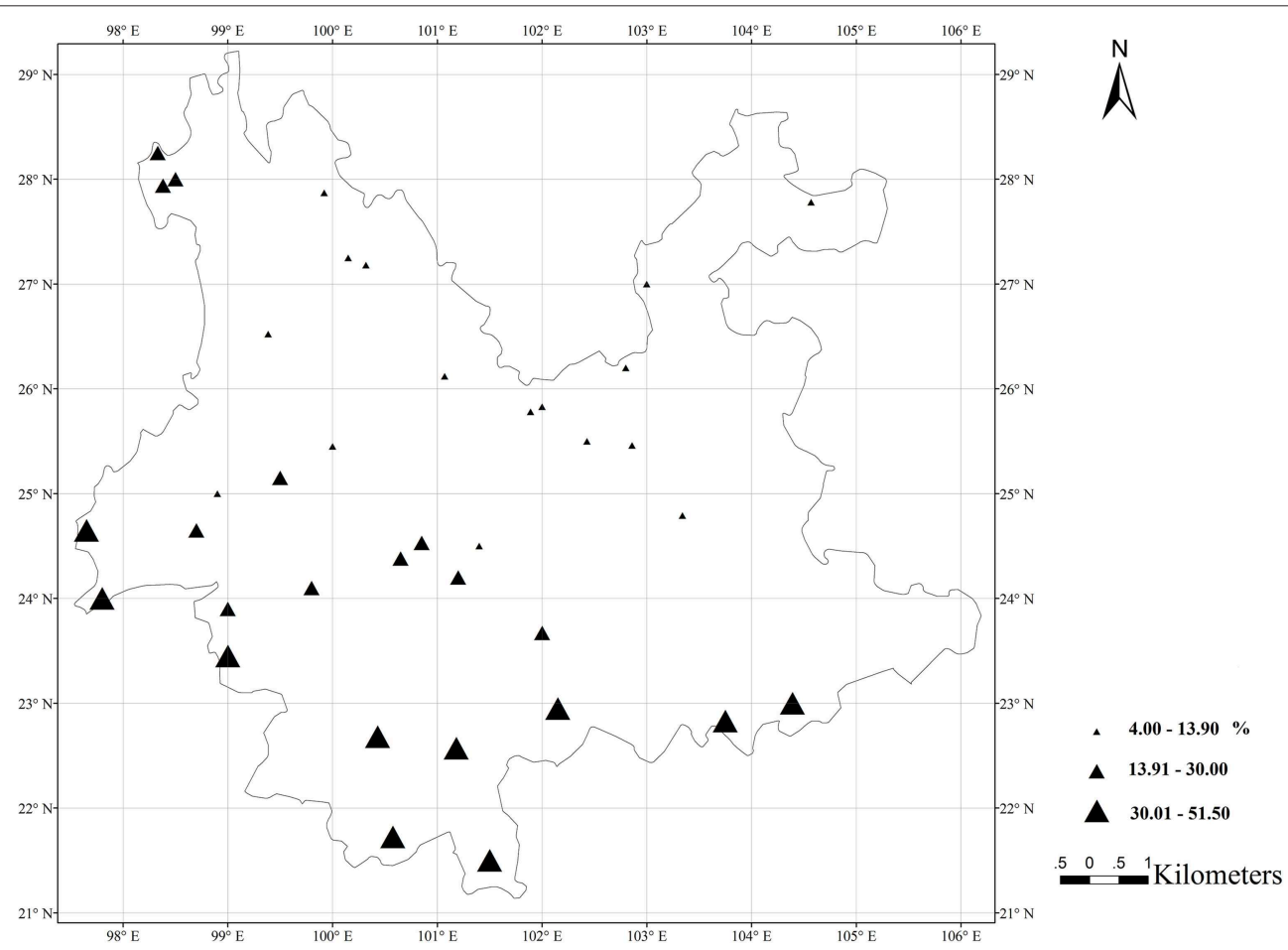

FIGURE 4 | The abundance pattern of the tropical Asian distributions of geographical elements across Yunnan. 


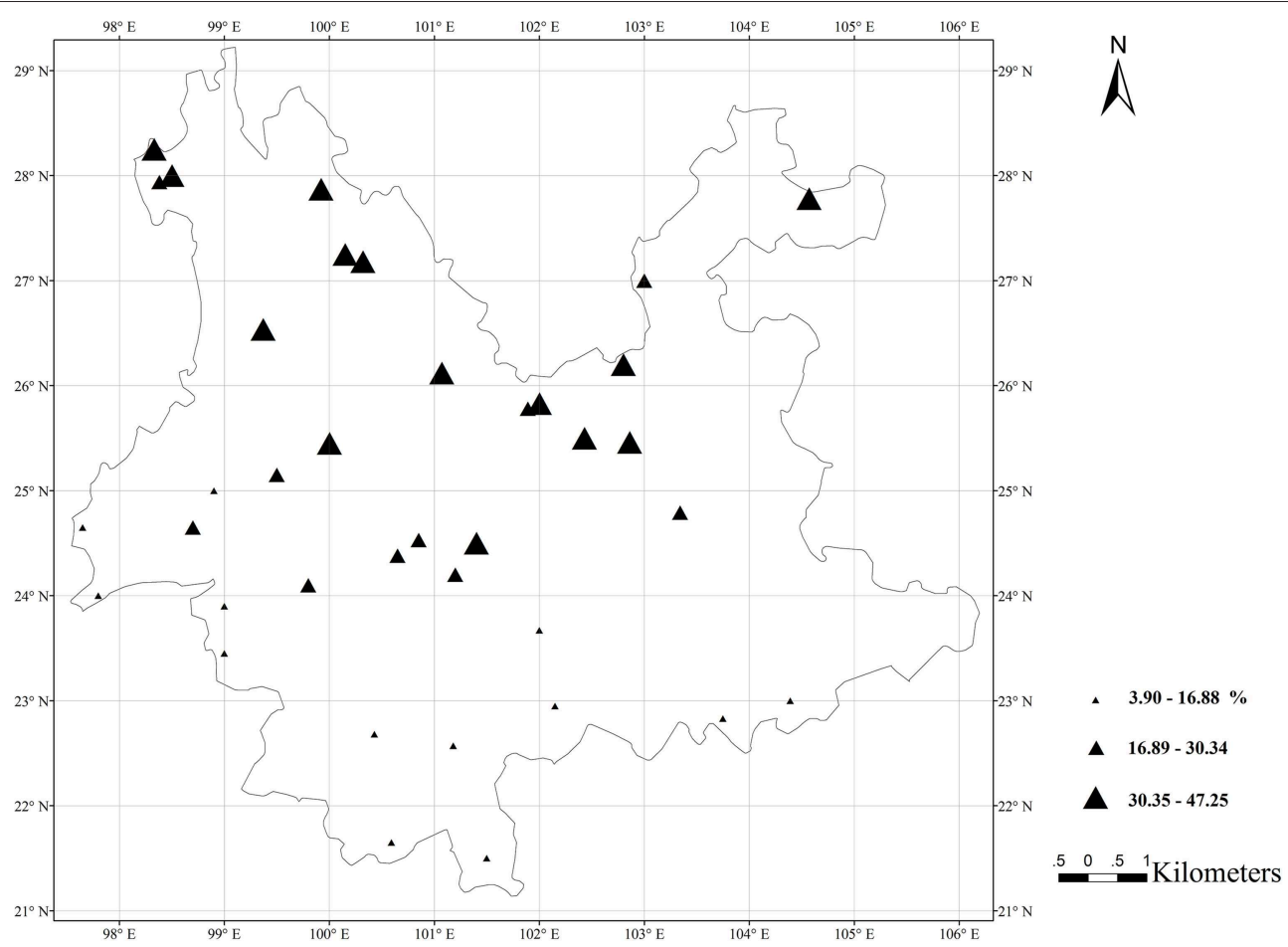

FIGURE 5 | The abundance pattern of the typical temperate distributions of geographical elements across Yunnan.

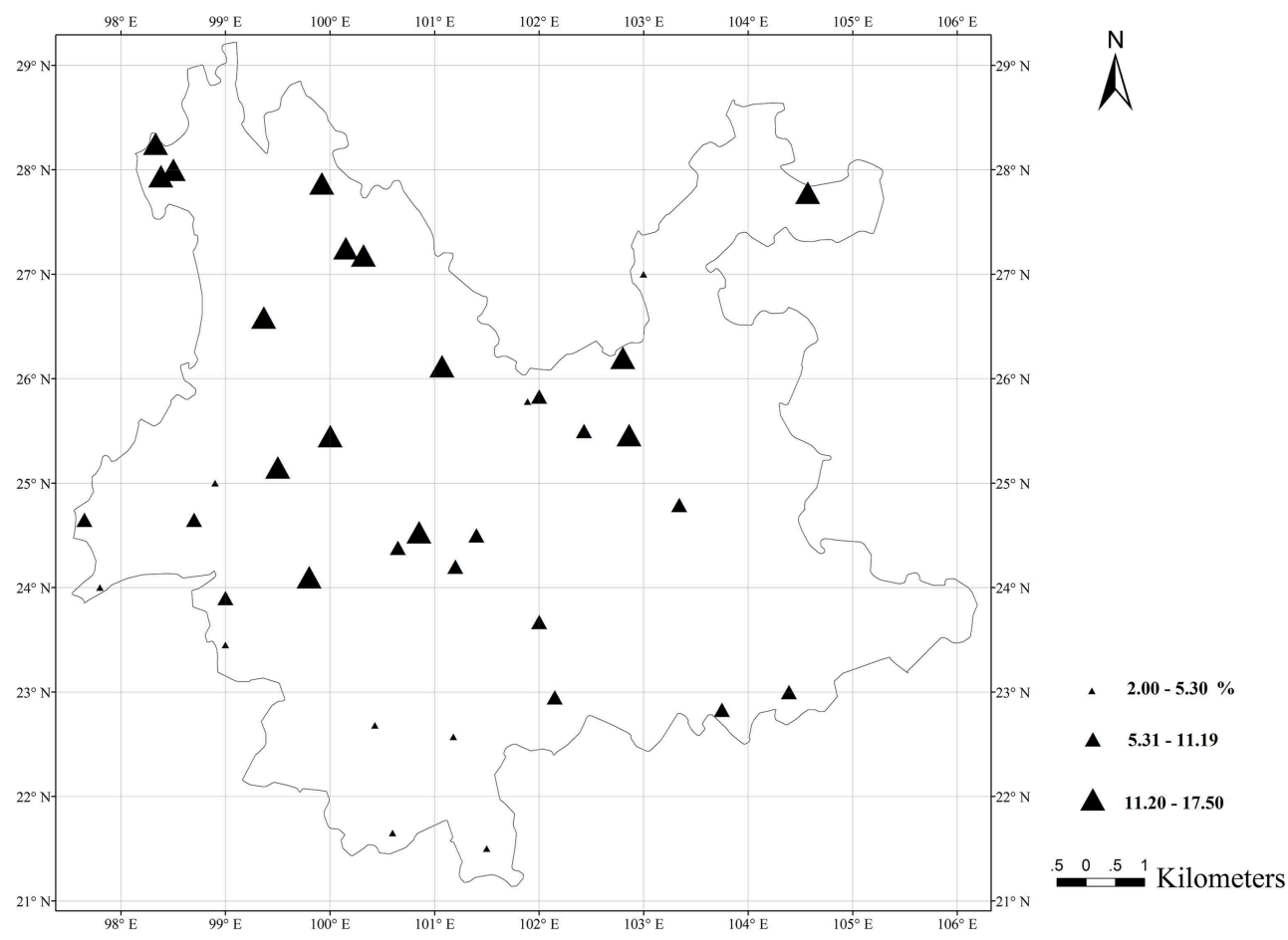

FIGURE 6 | The abundance pattern of the east Asia distributions of geographical elements across Yunnan. 
this article, I will address the correspondence by comparing the distribution patterns of Yunnan seed plants and the geological events.

\section{Materials and Methods}

A database of 38 regional floristic studies covering Yunnan was used to illustrate the distribution patterns of their floristic elements (Table 1). These studies were done mostly in well-protected nature reserves. The seed plant genera were assigned to 15 distribution patterns according to their worldwide geographical distributions, following Wu's classification (Wu, 1991) as follows: Cosmopolitan, Pantropic, Tropical Asia, and Tropical America disjunct, Old World Tropics, Tropical Asia to Tropical Australia, Tropical Asia to Tropical Africa, Tropical Asia, North Temperate, East Asia, and North America disjunct, Old World Temperate, Temperate Asia, Mediterranean region, West to Central Asia, Central Asia, East Asia, and Endemic to China. The Cosmopolitan distributions have little geographical significance and here are not used. Patterns of seed plant distributions across these regional floras were quantified at the generic level based on Wu's documentation. Here the tropical Asian elements are defined in sensu lato, including the typical tropical Asia distribution and tropical Asia to

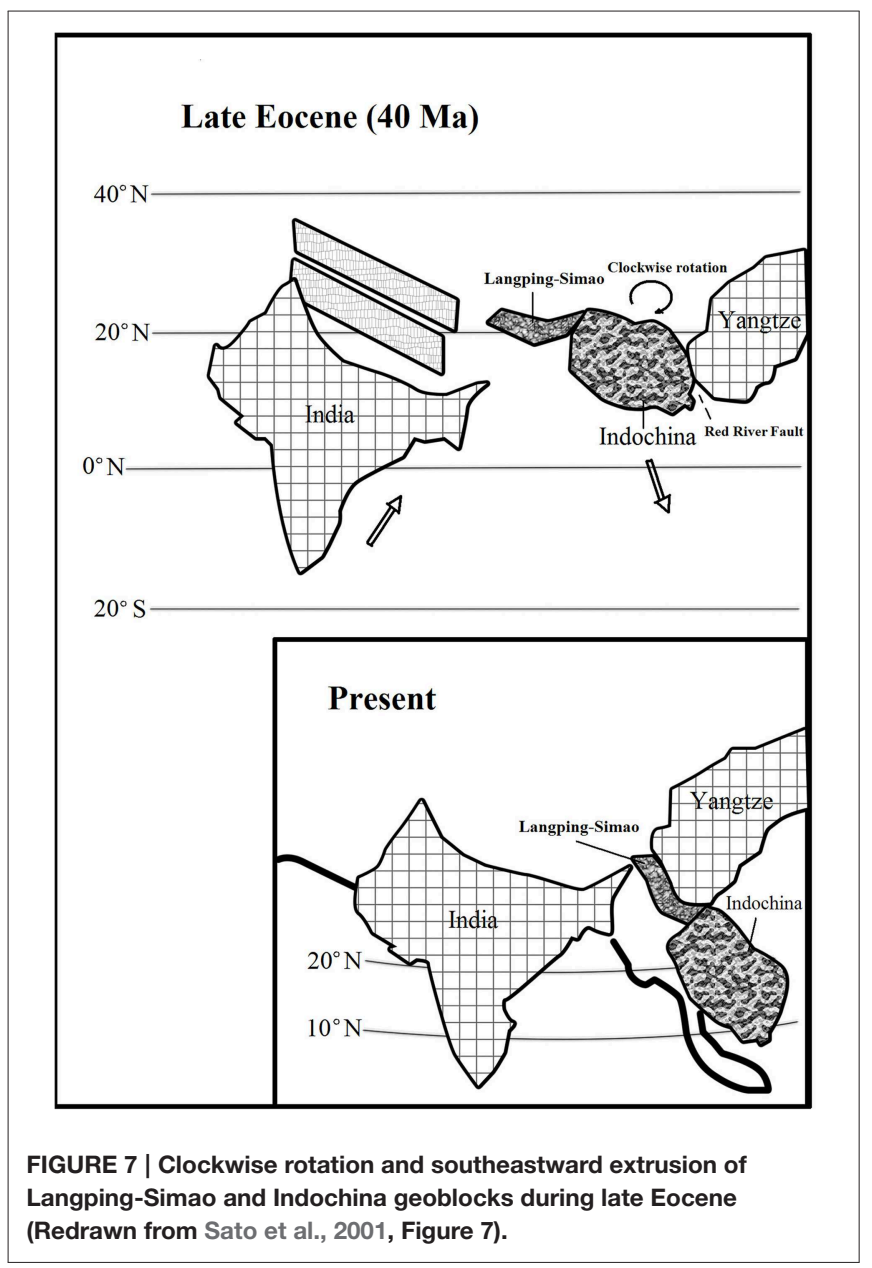

tropical Australia distribution. The typical temperate elements are defined in sensu lato, including the typical north temperate distribution, east Asia and north America disjunct, and Old World temperate distributions. Such pantropic elements, the tropical Asian elements in sensu lato, and the typical temperate elements in sensu lato, as well as the East Asia elements are recognized to be the four dominant elements, which contribute the majority not only in the total flora of Yunnan, but also in the regional floras in Yunnan. These four dominant geographical elements were abstracted from the regional floras and are used in our study (Table 1).

ArcView software was used for making abundance maps of the four geographical elements from the regional floras. The abundances were grouped into three classes, which were classified by natural breaks, with breakpoints between classes identified using Jenk's optimization, a default classification method in ArcViewGIS 3.1 that reduces variance within classes and maximizes variance between them. Graduated symbols were used.
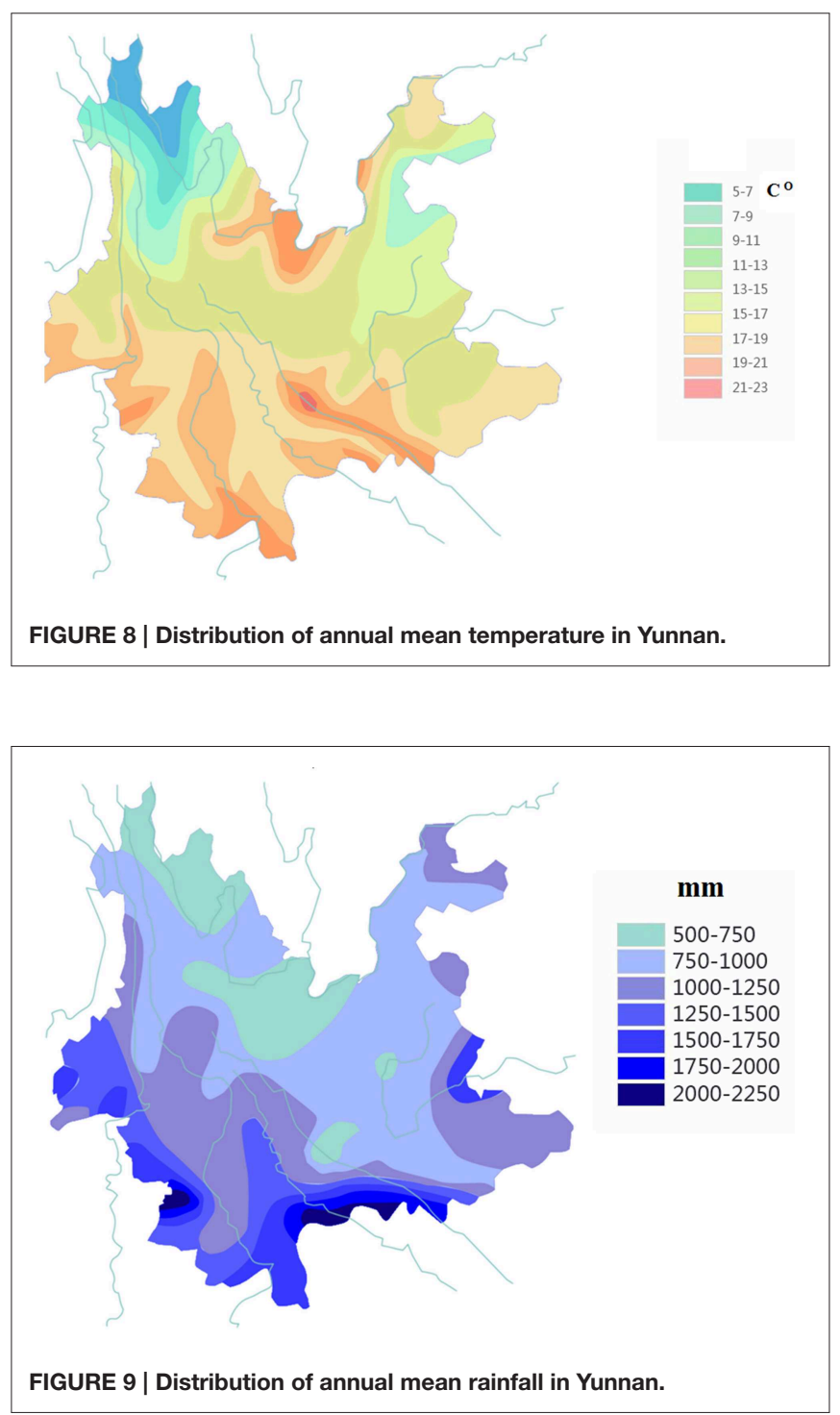
The Simao Terrane, which forms the present west and south parts of Yunnan, was displaced southward by $800 \mathrm{~km}$, together with a clockwise rotation of $30^{\circ}$. The rotation processes were believed active until at least the Miocene. This unique geological history may influence these abundant patterns of dominant geographical elements across Yunnan. Here the abundant patterns of geographical elements across Yunnan were used to discuss the relationship between the floristic geography and geological history of Yunnan.

\section{Results}

Genera with pantropc distributions contribute $13-41.88 \%$ of the regional floras across Yunnan. The abundance pattern of the pantropic genera shows little correspondence with latitude, but has high proportion at dry-hot valleys (Figure 3). The highest proportion, which makes of $41.88 \%$ of the total regional flora, is at the Yuanmou dry-hot valley of Jingshan rive in northern Yunnan, and the second highest proportion is at the dry-hot valley of Lujiang rive in western Yunnan. Genera with tropical Asian (sensu lato) distributions contribute 4\% (in northern Yunnan) to $51.5 \%$ (in southern Yunnan) of the regional floras across Yunnan. The abundance pattern shows that they occur mainly in southern and western Yunnan, and their proportions in regional floras declines abruptly in eastern, central and northern Yunnan (Figure 4). The typical temperate (sensu lato) genera contribute $3.9 \%$ (in southern Yunnan) to $47.25 \%$ (in northern Yunnan) of the regional floras across Yunnan (Figure 5). The east Asia genera contribute $2 \%$ in southern Yunnan to $17.5 \%$ in northern Yunnan (Figure 6).

Obviously, the tropical Asian genera show oblique abundance patterns across Yunnan. For example, in the Dulongjiang region in the far northwest of Yunnan $(28.25 \mathrm{~N}, 98.33 \mathrm{E})$, the tropical Asian genera contribute $18.11 \%$ of the total regional flora, while in the adjacent Lijian region $(27.18 \mathrm{~N}, 100.32 \mathrm{E})$, the tropical Asian genera only comprise $5.29 \%$.

\section{Discussion}

Geographical elements were considered related to latitude and altitude. The abundances of geographical elements

\section{References}

Cao, M., and Jing, Z. Z. (1989). Classification of vegetation in Qiaojia dry-hot river valley of Jinsha river, Yunnan. Acta Botan. Yunnan. 17, $324-336$.

Cao, S. W. (2004). Flora analysis of seed plants in Nuozadu Nature Reserve. J. West China For. Sci. 33, 46-51.

Cao, Y. H. (1993). A research on the flora of Nujiang dryhot valley in Lujiangba, Yunnan. Acta Botan. Yunnan. 15, 339-345.

Chen, H. H., Dobson, J., Heller, F., and Hao, J. (1995). Paleomagnetic evidence for clockwise rotation of the Simao region since the Cretaceous, A consequence of India-Asia collision. Earth Planet. Sci. Lett. 134, 203-217. doi: 10.1016/0012821X(95)00118-V across Yunnan show complicated patterns. The abundance pattern of the pantropic genera shows high proportion at dry-hot valleys despite latitude and altitude. The abundance pattern of the typical temperate genera shows some relations to latitude and altitude. The abundance pattern of the east Asia genera shows also some relations to latitude and altitude, but a higher proportion in southeast Yunnan.

In southern and eastern China, the abundances of tropical Asian genera have high correlations with latitudinal gradients (Zhu et al., 2007; Zhu, 2013). However, the abundances of these genera show oblique patterns across Yunnan, not latitudinal gradients. The tropical Asian genera unusually occur in a much higher percentages in western Yunnan than in eastern Yunnan. They decrease in proportion abruptly in northeast of Yunnan.

These abundance patterns of geographical elements across Yunnan show some correspondence with topography, but if we see the geological history of Yunnan (Figure 7), these abundance patterns correspond well to the clockwise rotation and southeastward extrusion of the Simao-Indochina geoblock. Compared with the distribution patterns of the annual mean temperature (Figure 8) and annual mean rainfall (Figure 9) in Yunnan, the abundances of geographical elements across Yunnan also do not show well correspondence with them as the usual.

Therefore, we consider that the relatively high proportion of tropical Asian genera in western and southwestern Yunnan matches the clockwise rotation of the Simao Terrane and the southeastward extrusion of the Simao-Indochina geoblock that facilitated migrations of SE Asian plants. These oblique patterns in Yunnan cannot be explained by climate alone, but can be explained at least partly by the geological history.

\section{Acknowledgments}

This research was supported by the National Natural Science Foundation of China, No. 41071040, 41471051, 31170195. The Database was put together by Yan Lichun. Prof. Richard Corlett helped improve the English of the article.

Cui, J. W., Liu, W. Y., Li, Y. H., She, Y. X., and Liu, L. H. (2005). The floristic elements of seed plants in stone forest limestone region, Yunnan Province. Guihaia 25, 517-525.

Ding, L., Du, F., Wang, J., Shi, C. Y., and Su, W. P. (2008). The flora of seed plants in northern Zhaotong, Yunnan province. Acta Botan. Yunnan. 30, 139-145. doi: 10.3724/SP.J.1143.2008.00139

Ding, Q., Li, X. W., and Fan, G. S. (2006). Study on flora of seed plants from dazhong mountain in the south central yunnan province. J. Southw. For. College 26, 6-9.

Duan, C. Z. (ed.). (1995). Scientific Investigation of Plant on Cangshan Mountain. Kunming: Yunnan Science, Technology Press, 238.

Funahara, S., Nishiwaki, N., Murata, F., Otofuji, Y., and Wang, Y. (1993). Clockwise rotation of the Red River fault inferred from paleomagnetic study of Cretaceous rocks in the Shan- Thai-Malay block of western Yunnan, 
China. Earth Planet. Sci. Lett. 117, 29-42. doi: 10.1016/0012-821X(93) 90115-P

Guo, Q. F. (1988). A preliminary study on the floristic plant geography of Shishan mountain Wuding, C. Yunnan. Acta Botan. Yunnan. 10, 183-200.

Harrison, T. M., Chen, W. J., Leloup, P. H., Ryerson, F. J., and Tapponnier, P. (1992). An early Miocene transition in deformation regime within the Red River fault zone, Yunnan, and its significance for IndoAsian tectonics. J. Geophys. Res. 97, 7159-7182. doi: 10.1029/92JB 00109

Kong, D. C. (2008). Plant diversity and integrated assessment for Gulinqing nature reserve in Maguang County. For. Invent. Plann. 33, 22-26.

Kunming Institute of Botany Chinese Academy of Sciences and Kunming Forestry Bureau. (2009). Scientific Investigation Report on Yunnan Jiaozixueshan Nature Reserve, Kunming: Kunming Institute of Botany.

Leloup, P. H., Lacassin, R., Tapponnier, P., Schärer, U., Dalai, Z., Liu, X. H., et al. (1995). The Ailao Shan-Red River shear zone Yunnan, China., Tertiary transform boundary of Indochina. Tectonophysics 251, 3-84. doi: 10.1016/00401951(95)00070-4

Li, G. C., Meng, G. T., Peng, F. S., and Zhang, J. Z. (2010). Preliminary study on the flora of the tracheophytes in Zixishan Natural Reserve. For. Surv. 153, 65-69.

Li, H. (1994). Delineation and feature of Dulongjiang region flora. Acta Botan. Yunnan. (Supp. XI), 1-100.

Li, H., Guo, H. J., and Dao, Z. L. (2000). Flora of Gaoligong Mountains. Beijing: Science Press, 344

Li, H. T., Du, F., and Wang, J. (2008). Studies on floristics of seed plants in Yuanjiang Nature Reserve in Yunnan Province. J. Trop. Subtrop. Bot. 16, 446-451.

Li, P. R., Meng, G. T., and Fang, X. J. (2009). Flora of seed plants in Wuding County, Yunnan. J. North. For. Univ. 37, 106-108.

Li, P. R., and Zeng, J. M. (2006). Preliminary study on flora of seed plants in Xianggelila County, Yunnan Province. J. Zhejiang For. College 23, 367-372.

Li, R. C., Yang, Y., Yang, Z. L., Zhao, L., Li, S. W., Li, X., et al. (2004). A floristic study on the seed plants from Yunlong reservoir area in Yunnan. Guihaia 24, 385-389.

Li, R., Dao, Z. L., and Ji, Y. H. (2007). A floristic study on the seed plants of the Northern Gaoligong Mountains in Western Yunnan, China. Acta Botan. Yunnan. 29, 601-615.

Liu, D. C., and Du, F. (1991). A preliminary study on flora of Jinguang Temple natural reserve in Western Yunnan. J. Southw. For. College 11, 115-124.

Liu, E. D., and Peng, H. (2010). Research on the Seed Plants and Forest Vegetation in Mount Yongdedaxueshan. Kunming: Yunnan Science, Technology Press, $1-501$.

Ma, K. P., Gao, X. M., and Yu, S. L. (1995). On the characteristics of the flora of Dongling Mountain area and its relationship with a number of other flora mountainous floras in China. Bull. Botan. Res. 15, 501-515.

Meng, G. Z., Chai, Y., Yuan, M. C., Ai, H. S., Li, G. X., Wang, Q., et al. (2013). Community characteristics of the mid-montane humid evergreen broad-leaved forest in Gaoligong Mountains, Yunnan. Sci. Silv. Sin. 49, $144-151$

Ou, X. K. (1988). The study of the flora in Yuanmou dry hot river valley. Acta Botan. Yunnan. 10, 11-18.

Peng, H. (1997). The endemism in the flora of seed plants in Mt. Wuliangshan. Acta Botan. Yunnan. 19, 1-14.

Rowley, D. B. (1996). Age of initiation of collision between India and Asia, a review of stratigraphic data. Earth Planet. Sci. Lett. 145, 1-13. doi: 10.1016/S0012$821 X(96) 00201-4$

Sato, K., Liu, Y. Y., Wang, Y. B., Yokoyam, M., Yoshioka, S., Yang, Z. Y., et al. (2007). Paleomagnetic study of Cretaceous rocks from Pu'er, western Yunnan, China, Evidence of internal deformation of the Indochina block. Earth Planet. Sci. Lett. 258, 1-15. doi: 10.1016/j.epsl.2007. 02.043

Sato, K., Liu, Y. Y., Zhu, Z. C., Yang, Z. Y., and Otofuji, Y. (1999). Paleomagnetic study of middle Cretaceous rocks from Yunlong, western
Yunnan, China, evidence of southward displacement of Indochina. Earth Planet. Sci. Lett. 165, 1-15. doi: 10.1016/S0012-821X(98) 00257-X

Sato, K., Liu, Y. Y., Zhu, Z. C., Yang, Z. Y., and Otofuji, Y. (2001). Tertiary paleomagnetic data from northwestern Yunnan, China, further evidence for large clockwise rotation of the Indochina block and its tectonic implications. Earth Planet. Sci. Lett. 185, 185-198. doi: 10.1016/S0012-821X(00) 00377-0

Schärer, U., Tapponnier, P., Lacassin, R., Leloup, P. H., Dalai, Z., and Ji, S. C. (1990). Intraplate tectonics in Asia, a precise age for large-scale Miocene movements along the Ailao Shan-Red River shear zone, China. Earth Planet. Sci. Lett. 97, 65-77. doi: 10.1016/0012-821X(90)90099-J

Wang, J., Ma, Q. Y., and Du, F. (2006a). Flora diversity characteristics of seed plants of Dawei Mountain National Nature Reserve in Yunnan province, China. Sci. Silv. Sin. 42, 8-15.

Wang, L. S., Kong, D. R., Ma, H. Y., and Peng, H. (2005). A preliminary study on floristics of spermatophyte from Mt.Xiaobaicaoling,Central Yunnan,China. Acta Botan. Yunnan. 27, 125-133.

Wang, Y. B., Du, F., and Cao, S. W. (2006b). Study on floristic phytogeography of seed plants in Xiaoheishan reserve, Yunnan Province. Guihaia 26, 261-267.

Wu, Z. Y. (1991). The areal-types of Chinese genera of seed plants. Acta Botan. Yunnan (Supp. IV), 1-139.

Xu, J. C. (ed.). (2003). Yunnan Huanglianshan Nature Reserve. Kunming: Yunnan Sci., Tech. Press.

Yan, L. C., Shi, J. P., Zhu, H., Peng, H., Liu, Y. H., and Wang, H. (2009). The studies on floristics of seed plants in Ailaoshan Region, Yunnan, China. J. Trop. Subtrop. Bot. 17, 283-291.

Yang, Y. M., and Du, F. (2004). Nangun River National Nature Reserve of China. Kunming: Yunnan Sci., Techn. Press, 1-386.

Yin, W. Y., Shu, Q. T., and Li, J. Y. (2007). A study on flora of spermatophyte of Tongbiguan nature reserve in Yunnan. J. Northw. Agric. For. Univ. 35, 204-210.

Yunnan Forestry Survey Institute. (2009). Scientific Investigation Report on Haba Snow Mt. Kunming: Nature Reserve, 1-408.

Yunnan Forestry Survey Institute. (2010). Scientific Investigation Report on Langping Yunling. Kunming: Nature Reserve, 1-222.

Zhang, Q. R., Du, F., Du, X. L., He, X., Zhuang, C. Z., Yan, X. H., et al. (2010). Flora of Seed Plants in Nanpeng River Nature Reserve in Yunnan Province. J. North. For. Univ. 38, 71-74.

Zhu, H. (1993). Floristic Plant geography on the dipterocarp forest of Xishuangbanna. Acta Botan. Yunnan. 15 233-252.

Zhu, H. (1997). Ecological and biogeographical studies on the tropical rain forest of south Yunnan, SW China with a special reference to its relation with rain forests of tropical Asia. J. Biogeogr. 24, 647-662. doi: 10.1111/j.13652699.1997.tb00075.x

Zhu, H. (2008a). The tropical flora of southern Yunnan, China, and its biogeographical affinities. Ann. Miss. Botan. Gard. 95, 661-680. doi: $10.3417 / 2006081$

Zhu, H. (2008b). Distribution patterns of genera of Yunnan seed plants with references to their biogeographical significances. Adv. Earth Sci. 23, 830-839.

Zhu, H. (2009). Read the Nature-Geological Wonder and Vegetation Geography of the Three Parallel Rivers Region in Northwest Yunnan. Beijing: Science Press, $1-155$.

Zhu, H. (2012). Biogeographical divergence of the flora of Yunnan, southwestern China initiated by the uplift of Himalaya and extrusion of indochina block. PLOS ONE 7:e45601. doi: 10.1371/journal.pone.00 45601

Zhu, H. (2013). Geographical elements of seed plants suggest the boundary of the tropical zone in China. Palaeogeogr. Palaeoclimatol. Palaeoecol. 386, 16-22. doi: 10.1016/j.palaeo.2013.04.007

Zhu, H. (2015). Biogeography of Shangri-la flora in southwestern China. Phytotaxa 203, 231-244 doi: 10.11646/phytotaxa. 203.3.2

Zhu, H., Chai, Y., Zhou, S. S., Wang, H., and Yan, L. C. (2015). Vegetation, floristic composition and species diversity in a tropical mountain nature reserve in southern Yunnan, SW China with implications to conservation. Trop. Conserv. Sci. 8, 528-547. 
Zhu, H., Ma, Y. X., Yan, L. C., and Hu, H. B. (2007). The relationship between geography and climate in the generic-level patterns of Chinese seed plants. J. Syst. Evol. 45, 134-166.

Zhu, H., and Yan, L. C. (2009a). Biogeographical affinities of the flora of southeastern Yunnan, China. Botan. Stud. 50, $467-475$.

Zhu, H., and Yan, L. C. (2009b). List of Seed Plants in the Ailao Mts. of Yunnan Province, China. Kunming: Yunnan Science, Technology Press, $1-731$.

Zhu, H., Zhao, C. J., Wang, H., Zhou, S. S., Shi, J. P., and Li, B. G. (2006a). A study on the flora of Caiyanghe Nature Reserve in Simao, Yunnan with references to the transition from tropical Asian flora to Eastern Asian flora. Bull. Botan. Res. $26,38-52$.
Zhu, H., Zhao, J. M., Li, L., and Si, H. H. (2006b). A study on the flora of the seed plants of tropical rain forest of Rui-li, SW Yunnan. Guihaia 26, 400-405.

Conflict of Interest Statement: The author declares that the research was conducted in the absence of any commercial or financial relationships that could be construed as a potential conflict of interest.

Copyright $\odot 2015 \mathrm{Zhu}$. This is an open-access article distributed under the terms of the Creative Commons Attribution License (CC BY). The use, distribution or reproduction in other forums is permitted, provided the original author(s) or licensor are credited and that the original publication in this journal is cited, in accordance with accepted academic practice. No use, distribution or reproduction is permitted which does not comply with these terms. 